\title{
Beiträge einreichen
}

Sie müssen auf jeden Fall einen Beitragstitel eingeben. Für den Alias gilt das gleiche, wie in Kap. 1 beschrieben. Eventuell wurde eine Kategorie vorgegeben dann müssen Sie diese übernehmen und können Sie nicht mehr ändern, sofern Sie lediglich Autor sind. Andernfalls wählen Sie eine passende Kategorie aus der Liste. Darunter können Sie Schlagwörter zum Beitrag angeben. Wählen Sie ein Schlagwort aus der Liste oder geben Sie ein neues ein, welches Sie mit einem ENTER auf der Tastatur abschließen. Beim nächsten Beitrag wird dieses Schlagwort automatisch in der Liste übernommen.

Die weiteren Einstellmöglichkeiten sind in den Kapiteln zuvor bereits erklärt worden.

Lediglich der Publisher kann zusätzlich den Status verändern. Das deswegen, weil erst im Status der Beitrag veröffentlicht werden kann. Und standardmäßig darf das erst die Benutzergruppe ab dem Publisher.

Eigene Beiträge können immer bearbeitet werden. Fremde Beiträge kann erst der Editor und der Publisher darf dann erst die Beiträge veröffentlichen. Etwas detaillierter dazu im Kap. 5 über den Workflow. 